\title{
MELTING-REFREEZING AT THE GLACIER SOLE AND THE ISOTOPIC COMPOSITION OF THE ICE
}

\author{
By J. JouzeL \\ (Centre d'Études Nucléaires de Saclay, Département de Physico-Chimie, F 91190, Gif-sur- \\ Yvette, France) \\ and R. A. Souchez \\ (Laboratoire de Géomorphologie, Faculté des Sciences, Université Libre de Bruxelles, B-1050 \\ Bruxelles, Belgium)
}

\begin{abstract}
A BSTRACT. A model for the isotopic composition in $\delta \mathrm{D}$ and $\delta^{18} \mathrm{O}$ of ice formed by refreezing at the glacier sole is developed. This model predicts relatively well the distribution of points representing samples from basal layers of an Arctic and an Alpine glacier on a $\delta \mathrm{D}-\delta^{18} \mathrm{O}$ diagram. The frozen fraction which is the part of the liquid that refreezes can be determined for each basal ice layer. This may have implications on the study of the ice-water system at the ice-rock interface.

RÉSUMÉ. Fusion et regel à la base d'un glacier et composition isotopique de la glace. Un modèle pour l'étude de la composition isotopique en $\delta \mathrm{D}$ et en $\delta^{18} \mathrm{O}$ de la glace formée par regel à la base du glacier est développé dans cet article. Ce modèle prédit relativement bien la distribution des points représentant des échantillons de glace basale d'un glacier polaire et d'un glacier alpin sur un diagramme $\delta \mathrm{D}-\delta^{18} \mathrm{O}$. La fraction gelee qui est la part d'eau qui regèle pour constituer une couche de glace basale peut être déterminee dans chaque cas. Ceci est susceptible d'avoir des implications sur les ètudes du comportement de la phase liquide à l'interface glacier-rocher.

ZuSAMmENFASSUNG. Regelation am Gletscherbett und die Isotopen-Zusammensetzung des Eises. Es wird ein Modell für die Zusammensetzung von Eis, das durch Regelation am Gletscherbett entstanden ist, aus den Isotopen $\delta \mathrm{D}$ und $\delta^{18} \mathrm{O}$ entwickelt. Dieses Modell beschreibt verhältnismässig gut die Verteilung von Stellen mit Proben aus grundnahen Schichten arktischer oder alpiner Gletscher auf einem $\delta \mathrm{D}-\delta^{18} \mathrm{O}$-Diagramm. Der Anteil an wiedergefrorener Flüssigkeit kann für jede Eisschicht am Untergrund bestimmt werden. Dies kann für das Studium des Eis-Wasser-Systems am Gletscherbett von Bedeutung sein.
\end{abstract}

\section{INTRODUCTION}

Regelation phenomena play a great role in theories explaining glacier basal sliding (Kamb and LaChapelle, 1964; Weertman, 1964; Kamb, 1970; Nye, 1970; Lliboutry, 1976). Melting and refreezing at the glacier sole is thus an important process in glacier studies. Such phase changes can result from pressure fluctuations in a glacier which is at the pressure-melting point but no substantial ice formation can be produced by such a process. Accretion by refreezing is possible because of the contribution of cold air even in the central part of the glacier or because of the presence of cold patches (Robin, 1976) or permafrost in the down-glacier direction (Weertman, 1961).

Water at the glacier bed can be in the form of a film which primarily accommodates the local transport of melt water associated with regelation sliding (Hallet, 1979). Through-flowing water appears to drain through a different hydraulic system, distinct channels at the ice-rock interface (Röthlisberger, 1972; Shreve, 1972). These waters produce a basal ice layer when they refreeze. This refreezing can be incomplete or total. It is of interest to know which situation occurs.

The aim of this paper is to provide a framework based on isotopic study for a better understanding of the melting-refreezing process at the interface. A model of the isotopic composition of ice developed by such a mechanism is described and tested against field evidence. The basal ice layers from an Arctic and an Alpine glacier were sampled in that context.

\section{SAMPLING PROCEDURE AND SAMPLE ANALYSIS}

Sampling procedure began with the removal of the upper $20 \mathrm{~cm}$ of ice exposed to the air. An 
aluminium coring device was then hammered into the ice and the sample extracted and transferred into a polyethylene bottle. Care was taken to fill the bottle entirely in order to minimize exchanges between melted ice and the air entrapped in the bottle. The melt water was transferred into $30 \mathrm{ml}$ glass bottles to avoid possible slight diffusion through polyethylene in the course of time. The bottles, equipped with a screw-top self-sealing propylene cap, were then sealed with paraffin wax to prevent evaporation.

The samples were analysed at the Centre d'Études Nucléaires de Saclay in France. The $\delta \mathrm{D}$ and $\delta^{18} \mathrm{O}$ obtained are expressed in per mil versus SMOW (Standard Mean Ocean Water with $\mathrm{D} / \mathrm{H}$ and ${ }^{18} \mathrm{O} /{ }^{16} \mathrm{O}$ respectively equal to 155.76 and 2005.2 p.p.m.). Precision of the measurements is $\pm 0.5 \%$ on $\delta \mathrm{D}$ and $\pm 0.1 \%$ on $\delta^{18} \mathrm{O}$.

\section{ISOTOPIC COMPOSITION OF BASAL ICE LAYERS FROM AN ARCTIC GLACIER}

A Canadian Arctic glacier, Aktineq Glacier, located on Bylot Island was sampled at its base for the isotopic composition of the ice. The samples were taken in the lower $3.5 \mathrm{~m}$ of a nearly vertical section about $14 \mathrm{~m}$ high on the left side of the glacier, $2.5 \mathrm{~km}$ from the snout. The lower ten metres of this section can easily be differentiated from the bulk glacier ice above in that they contain a negligible amount of bubbly ice and numerous debris layers.

Three main types of ice were encountered. The most frequent is coarse bubble-free ice occurring in layers 2 to $48 \mathrm{~cm}$ thick and showing imbricated ice crystals $2-4 \mathrm{~cm}$ in size with sinuous limits. A second type consists of bubble-free monocrystalline ice layers 0.1 to $0.3 \mathrm{~cm}$ thick. They are intimately associated with sandy layers of approximately the same thickness and consist of strongly elongated ice crystals. The two types of bubble-free ice described above are regularly distributed in the section. Two layers of bubbly ice, respectively 5 and $9 \mathrm{~cm}$ thick, constitute the third type. They are located in both cases just above a frozen debris band of about

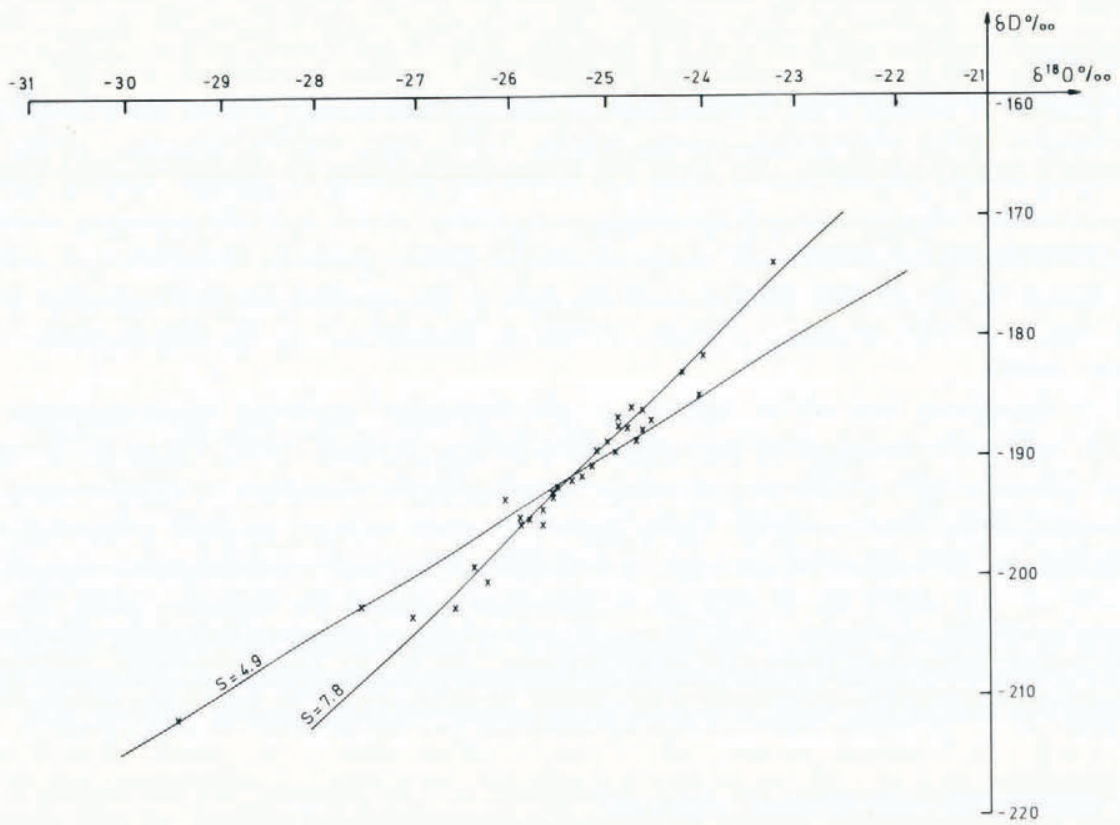

Fig. I. $\delta D-\delta^{18} O$ diagram for Aktineq Glacier ice samples. 
the same thickness. Ice crystals vary from $0.2 \mathrm{~cm}$ to $2 \mathrm{~cm}$ in size, with straight limits and polyhedral shapes. The numerous bubbles are either spherical or elongated in the plane of the layer. Independently, bubbly glacier ice was sampled on the glacier surface nearby.

To reveal processes in which the two heavy components of water $\left(\mathrm{HD}^{16} \mathrm{O}\right.$ and $\left.\mathrm{H}_{2}{ }^{18} \mathrm{O}\right)$ behave in different ways, it is convenient to plot the results on a graph where $\delta^{18} \mathrm{O}$ is the abscissa and $\delta \mathrm{D}$ the ordinate (Fig. 1). On this figure, two linear trends can be observed. Most of the points lie on a straight line with a slope $S=7.8$. The value of this slope, as well as the others given in the text, is determined by linear regression. This trend is known in the literature as being an important feature of the isotopic fractionation of water occurring during condensation or sublimation in simple equilibrium processes (Craig and others, 1963; Dansgaard, 1964; Merlivat and Jouzel, 1979). This relationship is generally true for fresh precipitation and thus valid for glacier ice which has not been submitted to major isotopic changes during and since its formation.

On this figure, a few samples obviously diverge from the line of slope 7.8 . They are located on another straight line with a slope of 4.9. Before analysing such a trend further, a theoretical development is needed.

\section{THE MODEL}

The diffusion coefficients of $\mathrm{HDO}$ and $\mathrm{H}_{2}{ }^{18} \mathrm{O}$ molecules in ice being very low (c. $10^{-11} \mathrm{~cm}^{2} \mathrm{~s}^{-1}$ ), melting occurs without isotopic change between compact ice and liquid. Indeed, as indicated by Moser and Stichler (1980), isotope fractionation which occurs at phase boundaries is not normally observed during melting or sublimation of glacier ice, whereas it does exist if the solid phase is in the form of porous snow or firn. The absence of fractionation during melting of ice was previously suggested by Friedman and others (1964). On the other hand, there is direct evidence by Arnason (1969) that an isotopic change occurs during percolation of water in snow but this is not directly applicable to our problem. Furthermore, Búason (1972), with the same experimental data, considers that fractionation does not occur in the phase change between solid and liquid but is probably the consequence of a partial recrystallization as indicated by a change in crystal size in the snow. From this, it seems realistic to consider that melting occurs without isotopic change between ice and liquid. Since the diffusion coefficients are relatively high (c. $10^{-5} \mathrm{~cm}^{2} \mathrm{~s}^{-1}$ ) in liquid water, which can be considered as isotopically homogeneous, refreezing takes place with an isotopic fractionation. The equilibrium coefficient between solid and liquid phases is called $\alpha_{\mathrm{SL}}$.

Let: $N_{0}$ be the total number of moles in the system or the number of moles in the liquid at the initial moment (the time when the liquid begins to refreeze),

$N_{\mathrm{s}}$ the number of moles in the solid phase at time $t$,

$N_{\mathrm{L}}$ the number of moles in the liquid phase at time $t$,

$R_{0}$ the isotopic ratio (for $\mathrm{D}$ or ${ }^{18} \mathrm{O}$ ) of the solution at the initial moment,

$R_{\mathrm{s}}$ the isotopic ratio (for $\mathrm{D}$ or ${ }^{18} \mathrm{O}$ ) of the solid phase near the liquid-solid interface at time $t$, $R_{\mathrm{L}}$ the isotopic ratio (for $\mathrm{D}$ or ${ }^{18} \mathrm{O}$ ) of the liquid, which is considered homogeneous, at time $t$.

Once formed, the solid has an isotopic composition that does not change in the course of time. At each step, the only isotope quantity (for $\mathrm{D}$ or ${ }^{18} \mathrm{O}$ ) brought to the solid phase is thus $\alpha_{\mathrm{SL}} R_{\mathrm{L}} \mathrm{d} N_{\mathrm{s}}$.

Now, if we consider a closed system, what is gained by the solid during refreezing is lost by the liquid. Therefore

$$
\alpha_{\mathrm{SL}} R_{\mathrm{L}} \mathrm{d} N_{\mathrm{s}}=-\mathrm{d}\left(R_{\mathrm{L}} N_{\mathrm{L}}\right)=-N_{\mathrm{L}} \mathrm{d} R_{\mathrm{L}}-R_{\mathrm{L}} \mathrm{d} N_{\mathrm{L}} .
$$


Since

$$
\begin{gathered}
\mathrm{d} N_{\mathrm{s}}=-\mathrm{d} N_{\mathrm{L}}, \\
R_{\mathrm{L}} \mathrm{d} N_{\mathrm{L}}\left(\alpha_{\mathrm{SL}}-1\right)=N_{\mathrm{L}} \mathrm{d} R_{\mathrm{L}} .
\end{gathered}
$$

Integrating,

$$
R_{\mathrm{L}}=R_{0}\left(\frac{N_{\mathrm{L}}}{N_{0}}\right)^{\alpha \mathrm{SL}-1}
$$

and, at the liquid-solid interface,

$$
R_{\mathrm{s}}=\alpha_{\mathrm{SL}} R_{0}\left(\frac{N_{0}-N_{\mathrm{s}}}{N_{0}}\right)^{\alpha \mathrm{SL}-1},
$$

and, if we use the $\delta$ notation,

$$
\delta_{\mathrm{s}}=\left[\alpha_{\mathrm{SL}}\left(1000+\delta_{0}\right)\left(\frac{N_{0}-N_{\mathrm{s}}}{N_{0}}\right)^{\alpha_{\mathrm{SL}-1}}-1000\right] .
$$

This equation is equivalent to that describing a Rayleigh process between vapour and liquid (Dansgaard, 1964).

It may be of interest to calculate, from Equation (1), the mean isotopic ratio of the solid formed each time a fraction of liquid ( $10 \%$ for example) changes state. We define $K=N_{\mathrm{s}} / N_{0}$ as the frozen fraction.

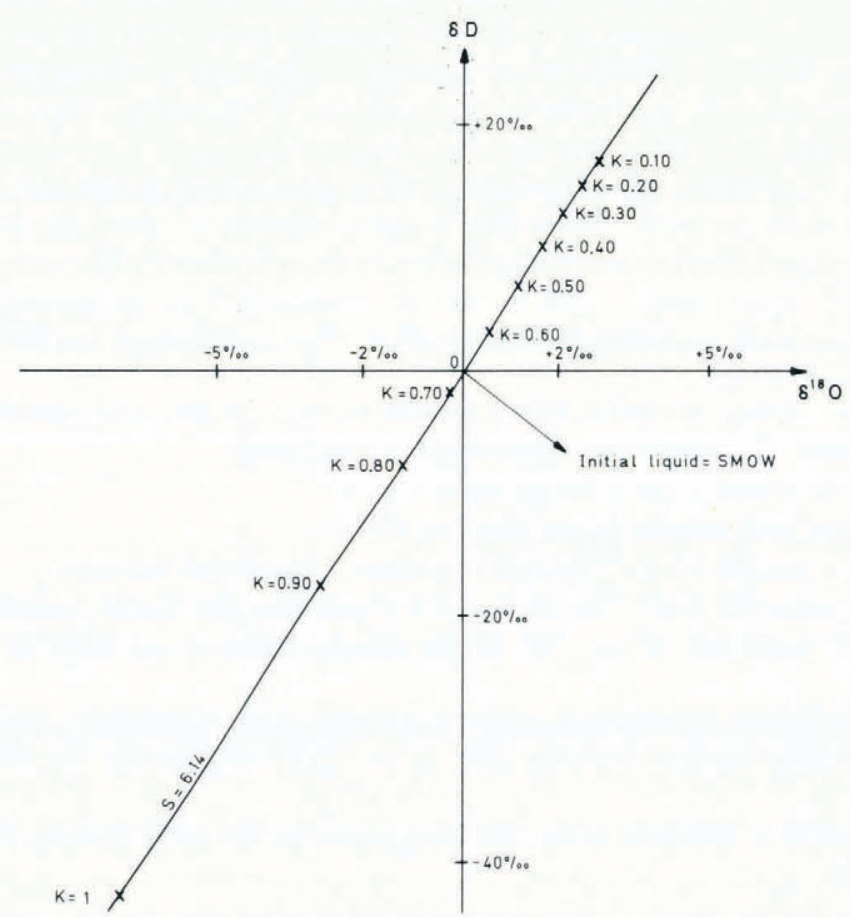

Fig. 2. $\delta$ values of ten successive fractions of ice formed during the freezing of SMOW. 
From integration of Equation (1) between $K-0.1$, and $K$,

$$
\bar{\delta}_{\mathrm{s}}=10\left(1000+\delta_{0}\right)\left[(1.1-K)^{\alpha \mathrm{SL}}-(1-K)^{\alpha \mathrm{SL}}\right]-1000 .
$$

On Figure 2, $\delta \mathrm{D}$ and $\delta^{18} \mathrm{O}$ are plotted on a classical graph for ten successive fractions of ice formed during freezing of water with initial $\delta \mathrm{D}$ and $\delta^{18} \mathrm{O}$ equal to 0 . The following equilibrium fractionation coefficients at $0^{\circ} \mathrm{C}$ were used (O’Neil, 1968):

$$
\begin{aligned}
& \alpha_{\mathrm{SL}}=\alpha=1.0186 \text { for } \mathrm{D}, \text { and } \\
& \alpha_{\mathrm{SL}}=\beta=1.003 \text { for }{ }^{18} \mathrm{O} .
\end{aligned}
$$

Points for each value of the frozen fraction $K$ are aligned along a straight line with a slope of 6.14. The value of this slope is close to the value (6.2) obtained using the ratio $S_{0}=$ $(\alpha-1) /(\beta-1)$, so its use as an estimate seems to be relevant.

When the initial liquid is not SMOW, the slope becomes

$$
S=S_{0} \frac{1000+\delta_{\mathrm{i}} \mathrm{D}}{1000+\delta_{\mathrm{i}}^{18} \mathrm{O}}
$$

$\delta_{\mathrm{i}} \mathrm{D}$ and $\delta_{\mathrm{i}}{ }^{18} \mathrm{O}$ being the values corresponding to the initial liquid.

Now, if the sampling procedure leads to a sample size of the same order of magnitude as the ice layer itself, a mean value for the whole ice layer is obtained. Instead of giving, as in Figure 2, the $\bar{\delta}$ values of ten successive fractions of ice formed during the freezing, we can compute from Equation (2) mean values for the entire ice layer. Figure 3 gives these mean values for ice formed

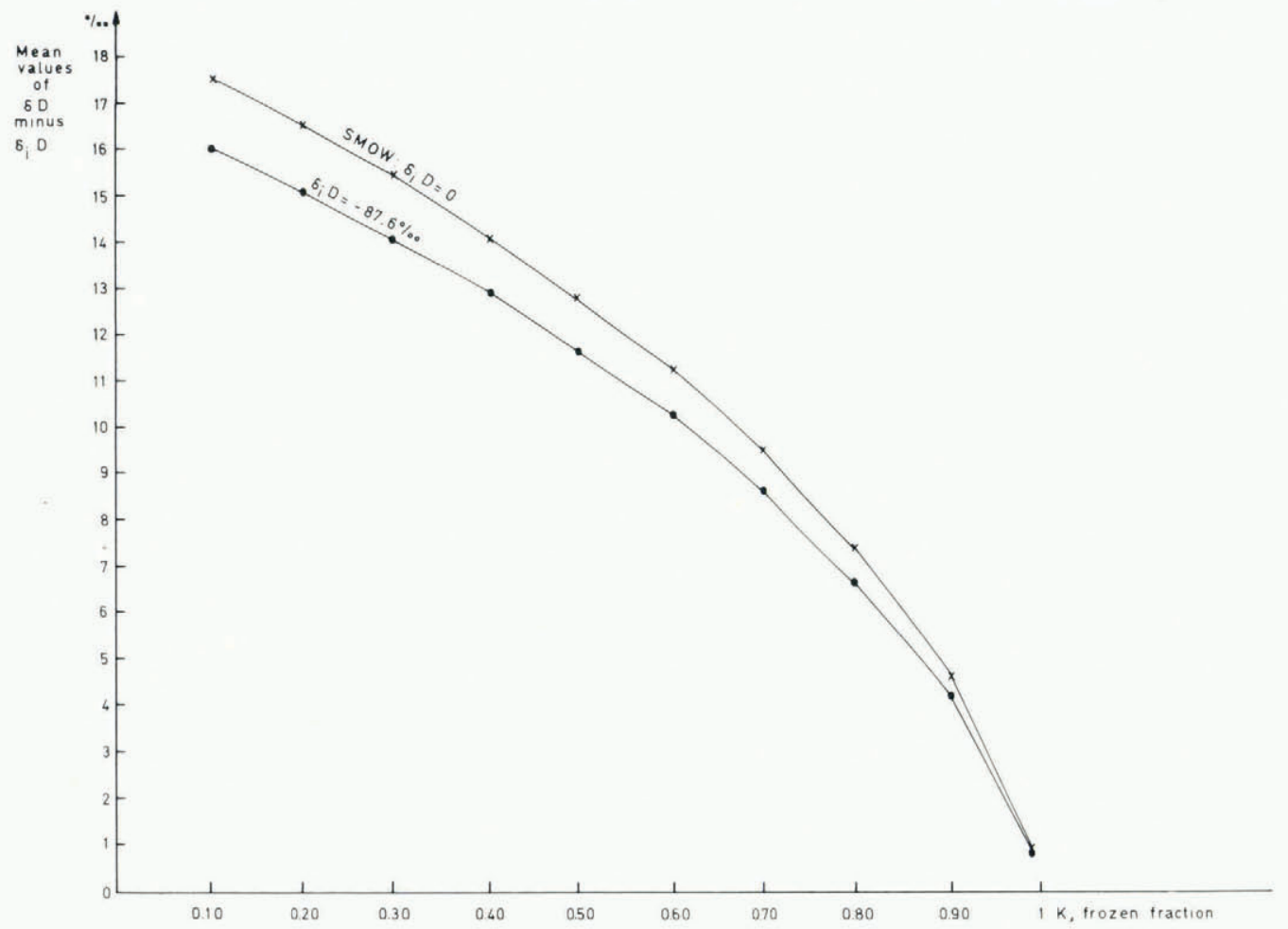

Fig. 3. Relationships between mean values in $\delta D$ of ice due to refreezing and the frozen fraction. 
by freezing water with $\delta_{\mathrm{i}} \mathrm{D}=0$ as a function of the frozen fraction $K$. The range for $\delta \mathrm{D}$ is between $18.6 \%$ as limiting value if $K$ is close to zero and $0 \%$ o for $K=1$; for $\delta^{18} \mathrm{O}$ the corresponding limits are $3 \%$ and $0 \%$. With a different initial liquid, the differences between mean values of $\delta \mathrm{D}$ (or $\delta^{18} \mathrm{O}$ ) and $\delta_{\mathrm{i}} \mathrm{D}\left(\right.$ or $\delta_{\mathrm{i}}{ }^{18} \mathrm{O}$ ) can be plotted so that we also reach zero for $K=1$.

\section{Explanation of the 4.9 SLOPE at AKtineq Glacier}

Taking into account the model described above, the initial liquid at Aktineq Glacier probably corresponds to the intersection between the two straight lines with slopes equal to 4.9 and 7.8 (Figure 1). So $\delta_{\mathrm{i}} \mathrm{D}=-192 \%$ o and $\delta_{\mathrm{i}}{ }^{18} \mathrm{O}=-25.3 \%$ o. Using these values in Equation (3), the calculated slope for the melting-refreezing process is 5.1. The slope of 4.9 obtained from the Aktineq samples is in close agreement with that of 5.1 predicted by the model. The three samples along the 4.9 slope impoverished in $\mathrm{D}$ and ${ }^{18} \mathrm{O}$ were taken within one bubbly ice layer. They represent the last stages in the refreezing process with theoretical $K$ values respectively 0.75 , 0.90 , and 0.95 . Mixing due to the trapping of liquid water or of another kind of ice with similar $\delta_{\mathrm{i}} \mathrm{D}$ and $\delta_{\mathrm{i}}{ }^{18} \mathrm{O}$ during refreezing can be responsible for a reduction of amplitude. A possibility is that residual water from a nearly complete refreezing invades an ice layer and becomes solid in much the same way as Koerner (1970) described for the growth of superimposed ice. If this mixing occurred, the $K$ values determined must be considered as minima.

\section{ISOTOPIC COMPOSITION OF BASAL ICE LAYER FROM AN ALPINE GLACIER}

Glacier de Tsanfleuron in the western Swiss Alps, was sampled at its base for the isotopic composition of the ice. The samples were taken in a natural subglacial cavity on the right side of

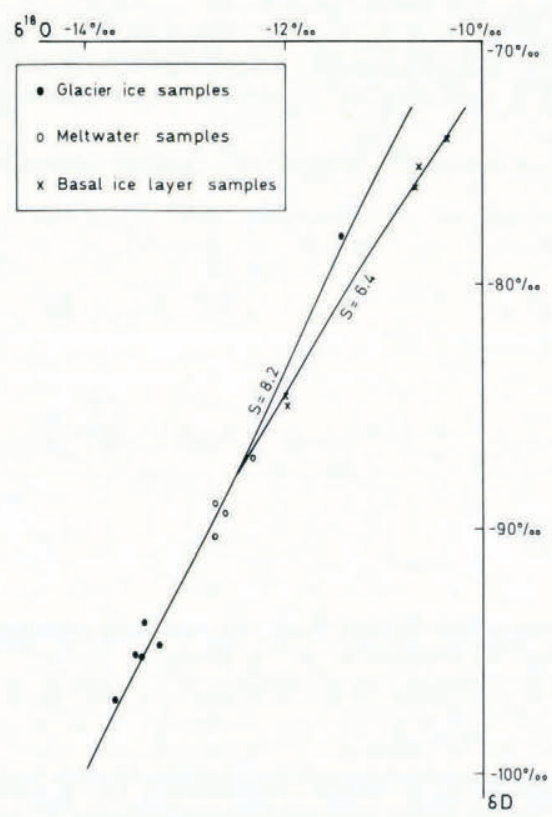

Fig. 4. $\delta D-\delta^{18} O$ diagram for glacier de Tsanfleuron ice samples. 
the glacier about $1 \mathrm{~km}$ from the snout. A basal ice layer (B.I.L.) composed of thin bubble-free ice layers $(0.1$ to $1 \mathrm{~cm}$ thick) interbedded with debris layers is visible at the base of the glacier at the level of the cavity. Its thickness reaches a few tens of centimetres. Above, glacier ice appears in striking contrast. Glacier ice, melt water from the roof of the cavity, and melt water running on the smooth bedrock in the cavity are represented in Figure 4 by points aligned on a straight line with a slope of 8.2 on the $\delta \mathrm{D}-\delta^{18} \mathrm{O}$ diagram. By contrast, points representing the thin ice layers of the B.I.L. are aligned along another straight line with a slope of 6.4. Souchez and Lorrain (1978) developed arguments on chemical grounds indicating that these ice layers in the B.I.L. are due to refreezing at the interface because of pressure fluctuations at the glacier base. At the intersection point between the two lines in Figure $4, \delta \mathrm{D}=-87.6 \%$ o and $\delta^{18} \mathrm{O}=-12.5 \%$ o. These values are between those of the four melt-water samples. It is thus relevant to consider them as initial liquid values. Equation (3) gives a theoretical slope value of 5.7. The correspondence with the slope predicted by the model is thus relatively good. The whole ice layer was considered for sampling, so that the isotopic composition of the samples represents a mean value for the layer. This enables us to use the cumulative curve of Figure 3 for an initial liquid value of $-87.6 \%$ o for $\delta$ D. $K$ values of the samples obtained in this way range from 0.25 to nearly 1 . This indicates that a wide variety of conditions prevails at the glacier base and that the whole B.I.L. is the result of a complex history of events.

\section{CONCLUSION}

Some ice samples taken at the glacier sole and in the basal ice layers are aligned on a $\delta \mathrm{D}-\delta^{18} \mathrm{O}$ diagram on a straight line with a slope different from that of precipitation. This has been observed here for the first time.

The situation appears to be the result of melting without isotopic change and refreezing with isotopic fractionation. The differentiation occurs because the isotopic fractionation coefficients are such that the $(\alpha-1) /(\beta-1)$ ratio is different from 8 . The model developed predicts relatively well the slope for ice samples resulting from this process, both in an Arctic glacier and in an Alpine glacier.

Water before refreezing has an isotopic composition given on the $\delta \mathrm{D}-\delta^{18} \mathrm{O}$ diagram by the point where the equilibrium line and the other line cross; it is called the initial liquid. The distance between a sample point and the point representing the initial liquid is a function of $K$, the frozen fraction. The equation given in the model for successively-formed ice fractions or a derived cumulative curve for the mean ice composition at each stage of freezing are used to estimate $K$, depending on the size of the sample compared with the thickness of the individual ice layer. The possibility thus exists of determining the frozen fraction in regelation ice at the glacier base. This may have implications for studies concerned with the ice-water system at the interface and on discussions related to the question of open versus closed distribution systems.

\section{ACKNOWLEDGEMENTS}

The Geological Survey of Canada and the Centre d'Études Nucléaires de Saclay are acknowledged respectively for permitting the field study and for analysing the samples.

The authors are much indebted to Dr L. Merlivat, head of the Laboratoire de Géochimie isotopique, Centre d'Études Nucléaires de Saclay, for fruitful discussions at an early stage of the paper and to J. L. Tison for his aid in sampling at Aktineq Glacier. 


\section{REFERENCES}

Arnason, B. 1969. The exchange of hydrogen isotopes between ice and water in temperate glaciers. Earth and Planetary Science Letters, Vol. 6, No. 6, p. 423-30.

Búason, T. 1972. Equation of isotope fractionation between ice and water in a melting snow column with continuous rain and percolation. Journal of Glaciology, Vol. 11, No. 63, p. 387-405.

Craig, H., and others. 1963. Isotopic exchange effects in the evaporation of water, by H. Craig, L. I. Gordon, and Y. Horibe. Journal of Geophysical Research, Vol. 68, No. 17, p. 5079-87.

Dansgaard, W. 1964. Stable isotopes in precipitation. Tellus, Vol. 16, No. 4, p. 436-68.

Friedman, I., and others. 1964. The variation of the deuterium content of natural waters in the hydrologic cycle, by I. Friedman, A. C. Redfield, B. Schoen, and J. Harris. Reviews of Geophysics, Vol. 2, No. 1, p. 177-89.

Hallet, B. 1979. Subglacial regelation water film. Journal of Glaciology, Vol. 23, No. 89, p. 321-34.

Kamb, W. B. 1970. Sliding motion of glaciers: theory and observation. Reviews of Geophysics and Space Physics, Vol. 8, No. 4, p. 673-728.

Kamb, W. B., and LaChapelle, E. R. 1964. Direct observation of the mechanism of glacier sliding over bedrock. Journal of Glaciology, Vol. 5, No. 38, p. 159-72.

Koerner, R. M. 1970. The mass balance of the Devon Island ice cap, Northwest Territories, Canada, $1961-66$. Journal of Glaciology, Vol. 9, No. 57, p. 325-36.

Lliboutry, L. A. 1976. Physical processes in temperate glaciers. Journal of Glaciology, Vol. 16, No. 74, p. $151-58$.

Merlivat, L., and Jouzel, J. 1979. Global climatic interpretation of the deuterium-oxygen 18 relationship for precipitation. Journal of Geophysical Research, Vol. 84, No. C8, p. 5029-33.

Moser, H., and Stichler, W. 1980. Environmental isotopes in ice and snow. (In Fritz, P., and Fontes, J. C., ed. Handbook of environmental isotope geochemistry. Vol. 1. New York, Elsevier, p. 141-78.)

Nye, J. F. 1970. Glacier sliding without cavitation in a linear viscous approximation. Proceedings of the Royal Society of London, Ser. A, Vol. 315, No. 1522, p. 381-403.

O'Neil, J. R. 1968. Hydrogen and oxygen isotope fractionation between ice and water. Journal of Physical Chemistry, Vol. 72, No. 10, p. 3683-84.

Robin, G. de Q. 1976. Is the basal ice of a temperate glacier at the pressure melting point? Journal of Glaciology, Vol. 16, No. 74, p. 183-96.

Röthlisberger, H. 1972. Water pressure in intra- and subglacial channels. Journal of Glaciology, Vol. 11 , No. 62, p. $177-203$.

Shreve, R. L. 1972. Movement of water in glaciers. Journal of Glaciology, Vol. 11, No. 62, p. $205-14$.

Souchez, R. A., and Lorrain, R. D. 1978. Origin of the basal ice layer from Alpine glaciers indicated by its chemistry. Journal of Glaciology, Vol. 20, No. 83, p. 319-28.

Weertman, J. 1961. Mechanism for the formation of inner moraines found near the edge of cold ice caps and ice sheets. Journal of Glaciology, Vol. 3, No. 30, p. 965-78.

Weertman, J. 1964. The theory of glacier sliding. Journal of Glaciology, Vol. 5, No. 39, p. 287-303. 